\title{
Acute Effects of "Delayed Postconditioning" With Periodic Acceleration After Asphyxia Induced Shock in Pigs
}

\author{
JOSE A. ADAMS, JORGE A. BASSUK, JAQUELINE ARIAS, HENG WU, VINOD JORAPUR, GERVASIO A. LAMAS, \\ AND PAUL KURLANSKY
}

\author{
Divisions of Neonatology [J.A.A., J.A.B., J.A., H.W.], and Cardiology [V.J., G.A.L.], Mt Sinai Medical Center, Miami Beach, Florida \\ 33140; Florida Heart Research Institute [P.K.], Miami, Florida 33137
}

\begin{abstract}
Asphyxia cardiac arrest and shock are models for whole body ischemia reperfusion injury. Periodic acceleration (pGz) achieved by moving the body on a platform is a novel method for inducing pulsatile vascular shear stress and endogenous production of endothelial nitric oxide, prostaglandin $\mathrm{E}_{2}$, tissue plasminogen activator, and adrenomedullin. The aforementioned are cardioprotective during and after ischemia reperfusion injury. We investigated whether $\mathrm{pGz}$, applied $15 \mathrm{~min}$ after return of spontaneous circulation (ROSC) would serve as an effective "delayed" post conditioning tactic to lessen acute reperfusion injury markers in a pediatric swine model of asphyxia induced shock. Asphyxia shock was induced in 20 swine weight $3.9 \pm 0.6 \mathrm{~kg}$. Fifteen minutes after ROSC, the animals were randomized to receive conventional mechanical ventilation (CMV, [Control]) or CMV with pGz. All animals had ROSC and no significant differences in blood gases or hemodynamics after ROSC. pGz treated had significantly less myocardial dysfunction post resuscitation, (i.e. better \% ejection fraction (EF), \% fractional shortening (FS), and wall motion score index) and lower biochemical indices of reperfusion injury (lower TNF- $\alpha$, IL-6, and Troponin I, and myeloperoxidase activity). Delayed postconditioning with $\mathrm{pGz}$ ameliorates acute post resuscitation reperfusion injury and improves myocardial dysfunction after asphyxia-induced shock. (Pediatr
\end{abstract} Res 64: 533-537, 2008)

$\mathrm{C}$ ardiac arrest is a model of whole body ischemia reperfusion injury (1-3). In the pediatric population, asphyxial cardiac arrest is one of the commonest causes of cardiac arrest, and is becoming a more frequently recognized cause in adults (4-6). Acute post arrest reperfusion injury is characterized by similar functional and biochemical changes, which occur after reperfusion injury. Post resuscitation myocardial dysfunction, inflammatory cascade activation, tissue injury, and reactive oxygen species activation are hallmarks of reperfusion injury (7-12). Postconditioning (Post C) performed immediately upon reperfusion, by pharmacological or mechanical methods ameliorates reperfusion injury (13-15). Postconditioning is accomplished by brief interruptions in reperfusion of the target organ, (ischemia Post C) or by ischemia of remote organs (remote Post C). Ischemia or remote postconditioning can only be performed under controlled circumstances owing

Received March 6, 2008; accepted May 29, 2008

Correspondence: Jose A. Adams, M.D., Mt. Sinai Medical Center, Division of Neonatology, 3-BLUM, 4300 Alton Road, Miami Beach, FL 33140; e-mail: tony@msmc.com

Supported by a Grant in Aid from the American Heart Association No. 0555133, and the Florida Heart Research Institute. to its initiation immediately upon reperfusion. Clearly, it would be desirable if a method were available which did not have such rigorous time constraints Whole body periodic acceleration $(\mathrm{pGz})$ might serve such a purpose. The application of pGz, sinusoidal head to foot motion produces pulsatile shear stress to the vascular endothelium. This causes release of endothelial derived vasoactive and cardioprotective substances, such as endothelial derived nitric oxide (eNO), prostaglandins, tissue plasminogen activator (t-PA), and adrenomedullin into the circulation $(3,16-19)$. These substances have been found to be cardioprotective in several ischemia reperfusion models (20-33).

The purpose of this study was to demonstrate the acute benefits of $\mathrm{pGz}$ as a means of delayed post $\mathrm{C}$ in CPR after asphyxia induced shock, e.g. institution of pGz 15 min after ROSC. These benefits include improved acute post resuscitation myocardial stunning and regional blood flows as well as decreased post resuscitation inflammatory cytokine surge and neutrophil infiltration.

\section{METHODS}

Animal preparation. The Institutional Animal Care and Use Committee of Mount Sinai Medical Center of Greater Miami approved all animal studies in compliance with the Animal Welfare Act. Twenty male Yorkshire juvenile pigs weighing $4 \pm 0.7 \mathrm{~kg}$ (age 2-3 mos) were used in this study. The animals were initially anesthetized with ketamine $(10 \mathrm{mg} / \mathrm{kg}$, intramuscularly) and maintained in a surgical plane of anesthesia with intravenous propofol. An airway was established by direct laryngoscopy and intubation carried out with a $5.0 \mathrm{~mm}$ cuffed endotracheal tube. The animals were paralyzed with pancuronium bromide $(0.1 \mathrm{mg} / \mathrm{kg}$ ) and ventilated with a volume ventilator (Puritan Bennett, Pleasanton, CA) at $10 \mathrm{~mL} / \mathrm{kg}$ tidal volume to achieve normal arterial carbon dioxide tension. $\mathrm{FiO}_{2}$ was maintained at 0.21 . Intravascular catheters were placed into the femoral artery to measure systemic blood pressure by connecting the fluid filled catheter to a pressure transducer (Transpac, Abbott Critical Care Systems, North Chicago, IL). A right atrial catheter was placed via the left external jugular vein for administration of fluids and drugs and the measurement of right atrial pressure. Arterial blood gases and electrolytes were measured using a blood gas analyzer (Rapid Lab TM348, Bayer Diagnostics, Tarrytown, NY). A left ventricular catheter was placed via the right carotid artery, and location confirmed by typical left ventricular waveforms, echocardiography and post mortem, for microsphere injections. An 5.5 F balloon-tipped flow-directed thermodilution pulmonary arterial catheter (OpticomTM, Abbot Laboratories, Chicago, IL) was inserted via the right

Abbreviations: CPR, cardiopulmonary resuscitation; CMV, conventional mechanical ventilation; EF, ejection fraction; eNO, endothelial nitric oxide; FS, fractional shortening; MPO, myeloperoxidase; pGz, periodic acceleration; Post C, postconditioning; ROSC, return of spontaneous circulation; WMSI, wall motion score index 
jugular vein and floated into the pulmonary artery under direct pressure monitoring for measurements of pulmonary arterial pressure, right atrial pressure, core body temperature and cardiac output. Placement was confirmed by the typical wave form of the pulmonary artery, and further confirmed at necropsy. The cardiac output was determined by thermodilution in triplicate using ice-cold saline. Body temperature was maintained between 37 and $39^{\circ} \mathrm{C}$ by means of heating pad. A standard 3-lead electrocardiogram (ECG) configuration was continuously monitored.

Platform design. The motion platform, which imparts whole body periodic acceleration, has been previously described $(34,35)$. It consists of a wooden platform powered by a linear displacement motor attached to an amplifier that is controlled by a sine wave generator (Non Invasive Monitoring Systems, Inc., North Bay Village, FL). The platform moves sinusoidally in a head-tofoot direction. The following link depicts a video of the pGz platform and motion: http://www.miamiheartresearch.org/pgzmotion/.

Experimental design. After surgical preparations, the paralyzed animals were observed for $30 \mathrm{~min}$ as baseline (BL). Asphyxia was induced by disconnecting the endotracheal tube from the mechanical ventilator, and occluding the endotracheal tube. Additionally, the animals were paralyzed to avoid gasping. After 2 min of reaching a mean blood pressure of $30 \mathrm{~mm} \mathrm{Hg}$ or below (Hypoxia Phase), the occlusion of the endotracheal tube was relieved and the animals underwent closed chest compression/ventilation CPR using a pneumatic piston device (Thumper, Michigan Instrument, Grand Rapids, MI). The compression force was adjusted to decrease the anteroposterior diameter of the chest by $25-30 \%$ with between 60 and $70 \mathrm{lb} / \mathrm{in}^{2}$; the ventilation was set at $10 \mathrm{~mL} / \mathrm{kg}$ with a compression ventilation ratio of 30:2. After return of spontaneous circulation (ROSC), e.g. an unassisted systolic blood pressure of $>50 \mathrm{~mm} \mathrm{Hg}$ for at least $15 \mathrm{~min}$, animals were randomly assigned to receive standard care, with conventional mechanical ventilatory support (CMV), to maintain normal blood gases (Control) or CMV and $\mathrm{pGz}(\mathrm{pGz})$. Fifteen minutes after ROSC, pGz was applied at $180 \mathrm{cpm}$ with $\mathrm{G}$ at \pm 0.4 and termed delayed postconditioning. Both groups received $\mathrm{FiO}_{2} 0.21$ during CPR and after ROSC. No further pharmacological intervention was given during CPR and after ROSC (Fig. 1). All animals were continuously monitored for $3 \mathrm{~h}$ and received propofol $(0.05 \mathrm{mg} / \mathrm{kg} / \mathrm{min})$ after ROSC, and then humanely euthanized while still under anesthesia with $100 \mathrm{mg} / \mathrm{kg}$ of sodium pentobarbital, consistent with the recommendation of the Panel on Euthanasia of the American Veterinary Medical Association. Tissues were sampled from vital organs for microsphere analysis and snap frozen at $-40^{\circ} \mathrm{C}$, and stored for future analysis.

Echocardiography. Echocardiography was performed with a HewlettPackard SONOS 2000 echocardiographic system with a 3.5/2.7 MHz transducer and recorded on VCR tapes. In each animal, two-dimensional short-axis view and M-mode tracings were performed according to the recommendation of the American Society of Echocardiography and as previously described by our laboratory $(8,36,37)$. All measurements were performed by an investigator blinded to the treatment assignment. Wall motion was assessed by the wall motion score index (WMSI) that was obtained by the sum of wall motion scores divided by the number of visualized segments. In this scoring system, higher scores indicate more severe wall motions abnormalities $(1=$ normal, 2 = hypo kinesis, 3 = akinesis, $4=$ dyskinesis, and $5=$ aneurysm) $(38,39)$.

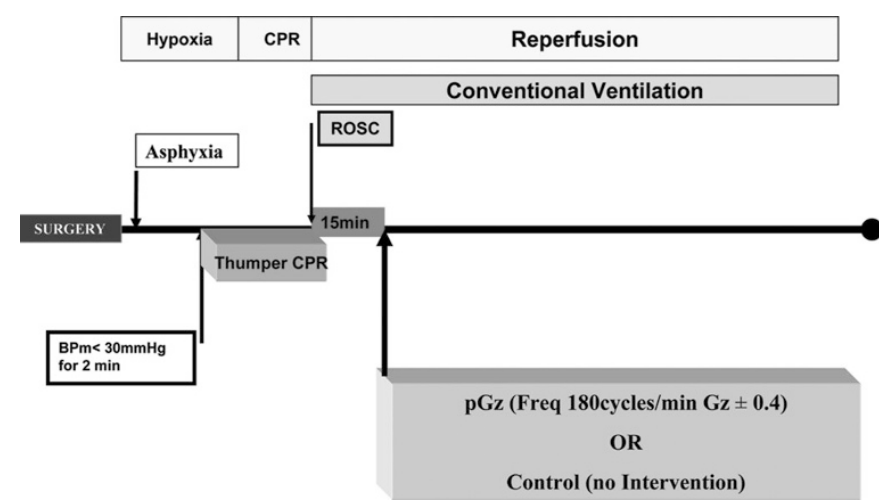

Figure 1. Schematic of the three phase asphyxial model. Hypoxia phase: asphyxia is induced and after loss of aortic pulsation (LOAP defined as aortic pulse pressure of $<2 \mathrm{~mm} \mathrm{Hg}$ ), 3 mins on nonintervention are observed. $C P R$ phase: 3 mins of CPR is performed with a THUMPER device or until return of circulation. Reperfusion phase: all animals remained on conventional mechanical ventilatory support to maintain normal arterial blood gases. In one group (pGz), pGz was begun 15 mins after return of circulation. No pharmacologic intervention is performed during CPR or after ROSC.
Biochemical analysis. Biochemical indices of reperfusion injury were obtained. Troponin I was measured as biochemical evidence of myocardial injury. Troponin I levels were measured with a pig cardiac Troponin I enzyme immunoassay kit (Life Diagnostics, Inc., West Cheater, PA). Markers of inflammatory activation, i.e. tumor necrosis alpha (TNF- $\alpha$ ), and IL-6 (IL-6) were measured by a porcine specific ELISA kit (R\&D Systems, Minneapolis, MN). A marker of tissue oxidative stress, myeloperoxidase activity (MPO) in the heart and lung was measured as previously described (40). MPO activity in each sample was determined by measuring the change in absorbance at 460 $\mathrm{nm}$. One unit of MPO activity is the amount of enzyme that will reduce $1 \mu \mathrm{M}$ peroxide per minute.

Regional blood flow. Regional blood flow measurements were performed as previously reported by our laboratory $(8,41,42)$. A bolus of $6 \times 10^{6}$ colored microspheres (Dye-Trak, Triton Technologies, San Diego, CA) suspended in 3 $\mathrm{mL}$ of a carrier solution of $0.9 \% \mathrm{NaCl}$ and $0.01 \%$ Tween- 80 was injected into the left ventricle. The reference blood sample was collected from the abdominal aorta. Blood flow was calculated as the tissue-derived numbers of microspheres referenced to arterial blood derived numbers of microspheres multiplied by the reference arterial blood withdrawal rate normalized per gram of tissue weight.

Statistical analyses. All values are reported as means \pm SD and where appropriate range and median values are reported. Continuous variables were evaluated by analysis of variance for repeated measures. For variables with significant differences, post hoc analysis was done using Tukey HSD for equal or unequal sample size. Comparison of discrete variables was evaluated by Fisher's exact test. Statistical analysis was performed using STATISTICA (StatSoft Inc., Tulsa OK). Statistical significance was taken as $p<0.05$.

\section{RESULTS}

Survival and electrocardiography. Time under anesthesia, and surgical procedure were not different between groups. The median time from endotracheal tube occlusion to reach $2 \mathrm{~min}$ of mean blood pressure of $30 \mathrm{~mm} \mathrm{Hg}$ or less was $10 \mathrm{~min}$ (range, 8-12 $\mathrm{min}$ ) (Hypoxia Time) and was not significantly different between the Control and pGz groups. Figure 1 shows the schematic of the protocol.

All animals had severe bradycardia upon initiation of CPR; none were in ventricular fibrillation. Mean heart rate immediately before start of CPR was $32 \pm 10 \mathrm{bpm}$, and $42 \pm 20 \mathrm{bpm}$ for Control and pGz, respectively ( $p=$ NS). All animals had ROSC. There were no significant differences in the CPR time between groups, pGz ( $3 \pm 1 \mathrm{~min})$ and Control (3.5 $\pm 0.5 \mathrm{~min})$.

Arterial blood gases and hemodynamics. Tables 1 and 2 list the arterial blood gases and hemodynamics in both groups over time. There were no significant differences between the

Table 1. Arterial blood gases and potassium levels

\begin{tabular}{llllll}
\hline \multicolumn{1}{c}{ Time } & \multicolumn{1}{c}{$\mathrm{pH}$} & $\mathrm{pCO}_{2}$ & $\mathrm{pO}_{2}$ & $\mathrm{HCO}_{3}$ & \multicolumn{1}{c}{$\mathrm{K}^{+}$} \\
\hline Control & & & & & \\
$\mathrm{BL}$ & $7.33(0.05)$ & $39(3)$ & $80(10)$ & $20(3)$ & $3.5(0.4)$ \\
$\mathrm{A} / \mathrm{H}$ & $6.86(0.11)^{*}$ & $85(20)^{*}$ & $14(4)^{*}$ & $14(3)$ & $3.6(0.2)$ \\
$\mathrm{CPR}$ & $7.06(0.13)$ & $46(20)$ & $77(10)$ & $12(3)$ & $6.3(1.2)^{*}$ \\
ROSC 30 min & $7.18(0.07)$ & $34(5)$ & $86(10)$ & $14(3)$ & $3.5(0.2)$ \\
ROSC 1 hr & $7.22(0.10)$ & $38(5)$ & $88(12)$ & $16(2)$ & $3.5(0.2)$ \\
ROSC 3 hr & $7.29(0.1)$ & $38(6)$ & $87(10)$ & $18(2)$ & $3.6(0.4)$ \\
$\mathrm{pGz}$ & & & & & \\
$\mathrm{BL}$ & $7.33(0.07)$ & $37(2)$ & $85(10)$ & $19(3)$ & $2.9(0.1)$ \\
$\mathrm{A} / \mathrm{H}$ & $6.92(0.11)^{*}$ & $83(20)^{*}$ & $20(10)^{*}$ & $14(3)$ & $3.5(0.1)$ \\
$\mathrm{CPR}$ & $7.12(0.11)$ & $44(7)$ & $60(6)$ & $13(4)$ & $5.9(1.5)^{*}$ \\
ROSC 30 min & $7.22(0.12)$ & $34(7)$ & $85(10)$ & $14(2)$ & $3.3(0.2)$ \\
ROSC 1 hr & $7.22(0.16)$ & $35(3)$ & $88(11)$ & $18(3)$ & $3.3(0.2)$ \\
ROSC 3 hr & $7.32(0.12)$ & $37(3)$ & $89(12)$ & $19(3)$ & $3.7(0.4)$ \\
\hline
\end{tabular}

Arterial blood gases and serum potassium levels at $\mathrm{BL}$, during asphyxia/ hypoxia (A/H), and after $30 \mathrm{~min}, 1 \mathrm{hr}$ and $3 \mathrm{hrs}$ of $\mathrm{ROSC} . \mathrm{PaO}_{2}, \mathrm{paCO}_{2}$ (torr), serum bicarbonate $\left(\mathrm{HCO}_{3}\right)$, serum potassium $\left(\mathrm{K}^{+}\right)$both in meq/dL.

$* p<0.05$ values compared with $\mathrm{BL}$ values. No significant differences between groups. 
Table 2. Hemodynamic data

\begin{tabular}{lcllc}
\hline \multicolumn{1}{c}{ Time } & BPm & PAPm & CPPm & CI \\
\hline Control & & & & \\
BL & $111(6)$ & $25(2)$ & $81(4)$ & $0.318(0.03)$ \\
A/H & $30(6)^{*}$ & $25(4)$ & $15(7)^{*}$ & \\
CPR & $92(8)$ & $35(3)$ & $49(10)^{*}$ & \\
ROSC 30 min & $89(7)$ & $42(2)^{* \dagger}$ & $64(9)^{*}$ & $0.280(0.03)$ \\
ROSC 1 hr & $89(8)$ & $25(2)$ & $62(6)^{*}$ & $0.310(0.07)$ \\
ROSC 3 hr & $85(6)$ & $25(2)$ & $63(8)^{*}$ & $0.305(0.01)$ \\
pGz & & & & \\
BL & $100(8)$ & $24(3)$ & $80(5)$ & $0.325(0.03)$ \\
A/H & $30(5)^{*}$ & $30(6)$ & $16(5)^{*}$ & \\
CPR & $85(8)$ & $37(5)^{*}$ & $63(20)$ & \\
ROSC 30 min & $106(11)$ & $23(4)$ & $75(9)$ & $0.285(0.10)$ \\
ROSC 1 hr & $87(7)$ & $23(5)$ & $74(10)$ & $0.256(0.10)$ \\
ROSC 3 hr & $84(8)$ & $25(6)$ & $77(6)$ & $0.330(0.10)$ \\
\hline
\end{tabular}

Hemodynamic data. Mean blood pressure (BPm) in $\mathrm{mm} \mathrm{Hg}$, mean pulmonary artery pressure (PAPm) and mean coronary perfusion pressure $(\mathrm{CPPm})$ in $\mathrm{mm} \mathrm{Hg}$. Cardiac Index $(\mathrm{CI})[\mathrm{CI}=($ Cardiac output $/ \mathrm{kg})](\mathrm{L} / \mathrm{kg} / \mathrm{min})$.

$* p<0.05$ values compared with $\mathrm{BL}$ values.

$\dagger p<0.05$ values Control vs pGz.

Control and $\mathrm{pGz}$ groups in arterial blood gas variables across time. Both groups had a significant increase in arterial $\mathrm{PaCO}_{2}$, a decrease in $\mathrm{PaO}_{2}$ and $\mathrm{pH}$ during hypoxia compared with $\mathrm{BL}$ but there was no significant difference between groups. There was a rise of serum potassium compared with BL in both groups. In Control and $\mathrm{pGz}$ animals during $\mathrm{CPR}, \mathrm{K}^{+}$was $6.3 \pm 1.2,5.9 \pm 1.5 \mathrm{meq} / \mathrm{dL}$, respectively $(p=0.07)$. There were no significant differences between groups for mean arterial blood pressure, coronary perfusion pressure and cardiac index. Pulmonary artery pressure significantly increased from BL in both groups during CPR and $30 \mathrm{~min}$ after ROSC. Control animals had an increase from $25 \pm 2 \mathrm{~mm} \mathrm{Hg}$ at BL to $35 \pm 3$ and $42 \pm 2 \mathrm{~mm} \mathrm{Hg}$ during CPR and $30 \mathrm{~min}$ after ROSC. pGz animals also had an increase from $24 \pm 3$ at BL to $37 \pm 5 \mathrm{~mm} \mathrm{Hg}$ during CPR. Fifteen minutes after ROSC, when $\mathrm{pGz}$ was applied for delayed postconditioning, mean pulmonary arterial pressure was $42 \pm 2 \mathrm{~mm} \mathrm{Hg}$ in the Control group and $23 \pm 4$ in the $\mathrm{pGz}$ group $(p<0.01)$.

Echocardiography. Myocardial stunning was present in all animals in both groups after ROSC. Ejection fraction (EF), fractional shortening (FS) and wall motion score index were severely impaired in Control animals at both 30 and $120 \mathrm{~min}$ after ROSC. Delayed postconditioning with $\mathrm{pGz}$ animals had significantly less myocardial dysfunction compared with Control group at 30 and 120 mins after ROSC (Fig. 2).

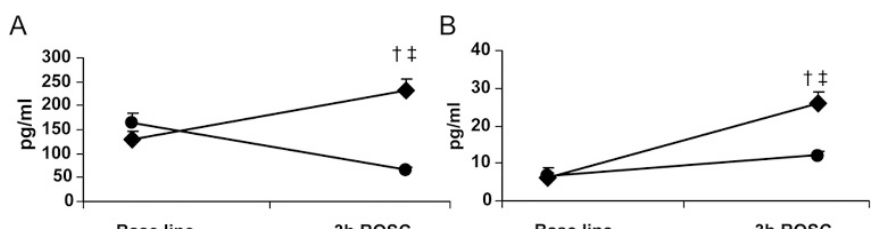

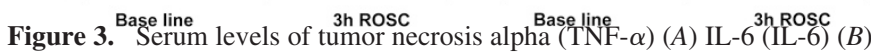
at BL and after $3 \mathrm{~h}$ ROSC. $\dagger p<0.05$ values compared with BL values. $\ddagger p<$ 0.05 values Control $(\diamond)$ vs pGz $(\bullet)$.

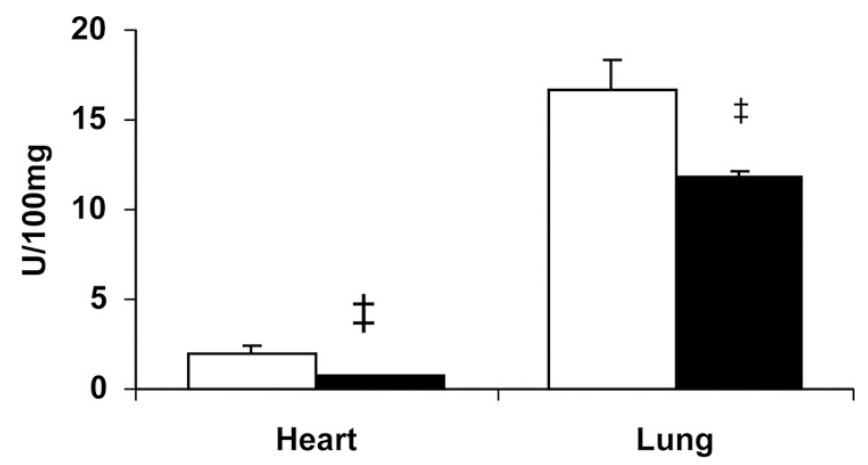

Figure 4. Myeloperoxidase activity in heart and lung tissue at completion of the experiment. $\ddagger p<0.01$ values Control $(\square)$ vs pGz (口).

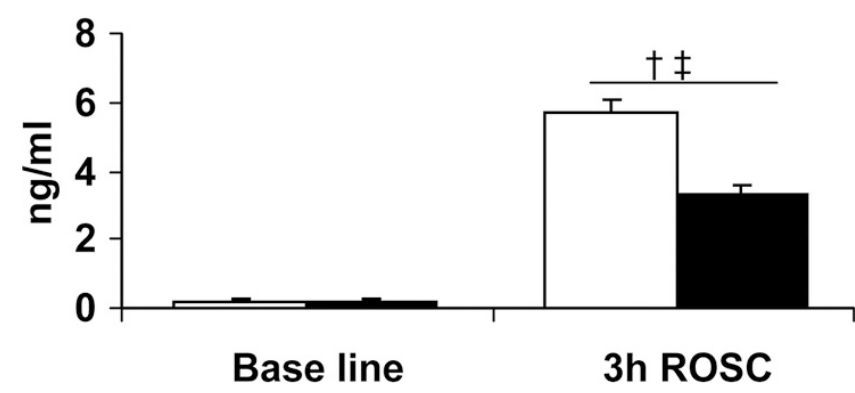

Figure 5. Serum troponin I levels at BL and after 3 h ROSC. $\dagger p<0.01$ values compared with BL values. $\ddagger p<0.01$ values Control $(\square)$ vs pGz (ם).

Biochemical indices of reperfusion. Three hours after ROSC, the surge in inflammatory markers, e.g. IL-6 (IL-6) and tumor necrosis alpha (TNF- $\alpha$ ) was attenuated in the $\mathrm{pGz}$ animals compared with the Controls $(p<0.05)$ (Fig. 3). Oxidative stress and neutrophil infiltration as evidenced by myeloperoxidase activity was also attenuated $3 \mathrm{~h}$ after ROSC in both heart and lungs of pGz treated animals $(p<0.01)$ (Fig. 4). Troponin I, a marker of cardiac tissue injury, was attenuated in pGz treated animals $3 \mathrm{~h}$ after ROSC compared with Control $(p<0.01)$ (Fig. 5).
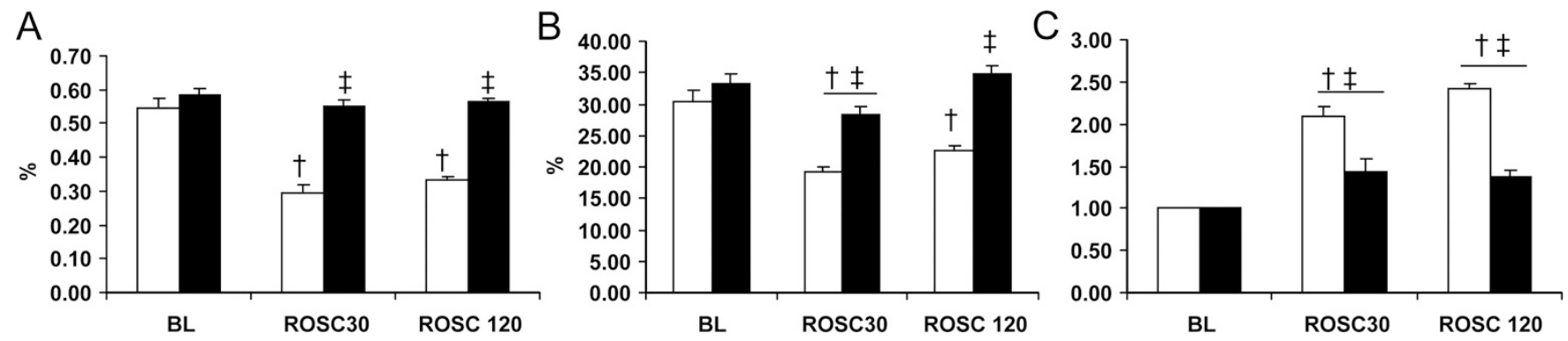

Figure 2. Echocardiographic measurements at $\mathrm{BL}$ and after $30 \mathrm{mins}$ and $120 \mathrm{~min}$ after ROSC. $A$, Percent EF. $B$, Percent FS. $C$, WMSI. $\dagger p<0.05$ values

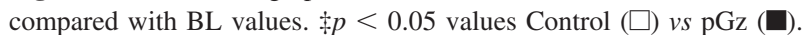




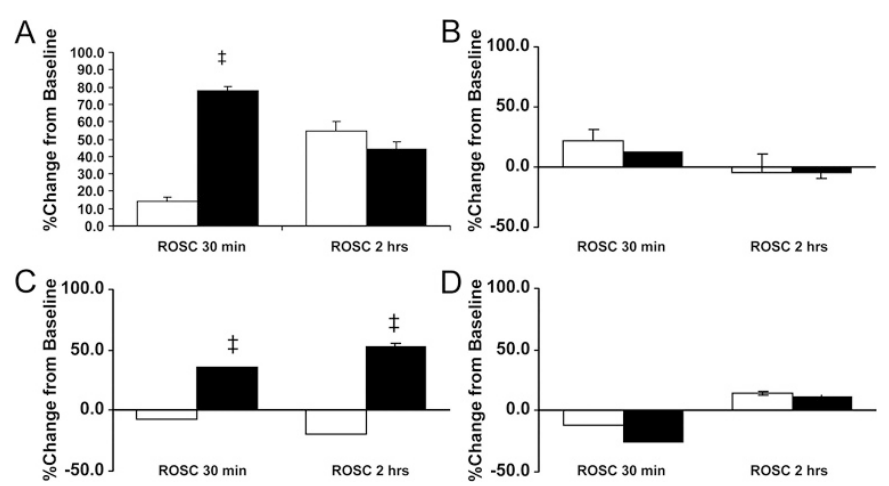

Figure 6. Regional blood flows in: $A$, Cerebral cortex, $B$, Cerebellum. $C$, Combined right and left ventricles. $D$, Kidney as percent change from BL values for each organ. $\ddagger p<0.05$ values Control $(\square) v s$ pGz (ם).

Regional blood flows. Thirty minutes after ROSC, regional blood flow in the cerebral cortex and cardiac ventricles was significantly increased in $\mathrm{pGz}$ animals compared with Control $(p<0.01)$. This increase persisted in the ventricles $2 \mathrm{~h}$ after ROSC, but not in cerebral cortex where it declines to $44 \pm 8 \%$ of BL. There were no significant differences between $\mathrm{pGz}$ and Control groups in cerebellar or renal regional blood flows (Fig. 6).

\section{DISCUSSION}

Unlike classical postconditioning whereby the postconditioning stimulus is performed immediately at reperfusion, we applied pGz 15 min after ROSC. This intervention, which we term 'delayed postconditioning' because of the delayed institution of its application, still renders $\mathrm{pGz}$ an effective strategy to reduce injury induced by whole body ischemia reperfusion.

Classical postconditioning is defined as a series of brief interruptions in reperfusion applied at the immediate onset of reperfusion $(43,44)$. Na et al. in cats $(44 a)$ and Zhao et al. in canines (45) first demonstrated this phenomenon in models of coronary artery occlusion. $\mathrm{Na}$ et al. found postconditioning to prevent reperfusion induced venticular fibrillation (44a). Zhao et al. found reduced myocardial infact size and neutrophil accumulations (45). They found reduced myocardial infarct size and neutrophil accumulations. The mechanisms involved in postconditioning have been the subject of numerous investigations. Important signaling mechanisms have been identified during ischemia reperfusion, the p42/44 ERK1/2 and PI3-Akt pathways collectively termed RISK pathway. These are innate cellular survival kinase pathways which when stimulated inhibit proapoptotic pathways, stimulate eNOS and activate $\mathrm{K}_{\text {АTP }}$ channels (46-48). Endothelial derived NO (eNO) inhibits the mPTP (mitochondrial transitional pore) and attenuates necrosis and apoptosis $(49,50)$. Classical ischemic postconditioning activates components of the RISK pathway (PI3-Akt and ERK1/2) (43,49-53).

Endothelial derived NO and prostaglandins are critical during and after whole body ischemia reperfusion injury. Inhibition of eNO or prostaglandins before whole body ischemia reperfusion produces poorer survival and functional outcome $(3,54,55)$. Our laboratory has shown that pGz through increased pulsatile shear stress increases eNO, prostaglandin $\mathrm{E}_{2}$, and ad- renomedullin (17-19). These have all been found to be cardioprotective in various models of ischemia reperfusion. Thus, $\mathrm{pGz}$ postconditioning after asphyxial shock may exert its beneficial effects through these endothelial derived mediators.

In contrast to classical postconditioning, $\mathrm{pGz}$ in asphyxiainduced shock was applied $15 \mathrm{~min}$ after ROSC. This time lapse was done to better mimic a usual clinical scenario of asphyxic cardiac arrest, whereby 15 min might elapse after ROSC before the patient being transported to a hospital facility. Even this delayed pGz application, beneficial effects occur as evidenced by attenuated and improved functional as well as biochemical indices of reperfusion injury. These findings with $\mathrm{pGz}$ postconditioning contrast to those reported by other investigators of a loss of cardioprotection when the postconditioning stimuli are delayed even a few minutes (15). These differences can possibly be accounted for by taking into consideration that classical postconditioning stimuli when invoked may alter the upstream signaling RISK pathway or others. pGz postconditioning effect involves more downstream signaling, such as eNOS, prostaglandins, and adrenomedullin.

There are limitations to the present work, which need to be acknowledged. Our asphyxia cardiac arrest model was performed on healthy anesthetized swine and therefore we cannot extrapolate our conclusions to diseased states, or infer any potentially confounding effects of anesthesia. Both groups received the same anesthetic and dosing. We also did not determine whether or not the cardioprotection afforded by delayed pGz (15 min after ROSC) can still be obtained if pGz were to be applied beyond this time period, or even enhanced if applied before this time period. The acute period of observation in our study allows us to draw conclusions on the acute cardiovascular and biochemical changes since longer periods of study would be required to determine whether any additional gains could be obtained on neurologic outcomes. The present study demonstrates that $\mathrm{pGz}$ applied $15 \mathrm{~min}$ after ROSC from asphyxia induced shock (delayed postconditioning) decreases acute post resuscitation myocardial stunning, improves regional blood flow to the heart and transiently to cerebral cortex, decreases indices of tissue damage, reduces inflammatory cytokine surge as well as oxidative stress markers and neutrophil infiltration compared with standard supportive interventions.

Acknowledgments. We thank Dr. Marvin Sackner for his editorial assistance of this manuscript, and Dr. Dongmei $\mathrm{Wu}$ for technical assistance.

\section{REFERENCES}

1. Wiklund L, Sharma HS, Basu S 2005 Circulatory arrest as a model for studies of global ischemic injury and neuroprotection. Ann N Y Acad Sci 1053:205-219

2. Adams JA, Wu D, Bassuk J, Arias J, Lozano H, Kurlansky P, Lamas GA 2007 Nitric oxide synthase isoform inhibition before whole body ischemia reperfusion in pigs: vital or protective? Resuscitation 74:516-525

3. Adams JA 2006 Endothelium and cardiopulmonary resuscitation. Crit Care Med 34:S458-S465

4. Donoghue AJ, Nadkarni VM, Elliott M, Durbin D 2006 Effect of hospital characteristics on outcomes from pediatric cardiopulmonary resuscitation: a report from the national registry of cardiopulmonary resuscitation. Pediatrics 118:995-1001 
5. Donoghue AJ, Nadkarni V, Berg RA, Osmond MH, Wells G, Nesbitt L, Stiell IG 2005 Out-of-hospital pediatric cardiac arrest: an epidemiologic review and assessment of current knowledge. Ann Emerg Med 46:512-522

6. Gerein RB, Osmond MH, Stiell IG, Nesbitt LP, Burns S 2006 What are the etiology and epidemiology of out-of-hospital pediatric cardiopulmonary arrest in Ontario, Canada? Acad Emerg Med 13:653-658

7. Girn HR, Ahilathirunayagam S, Mavor AI, Homer-Vanniasinkam S 2007 Reperfusion syndrome: cellular mechanisms of microvascular dysfunction and potential therapeutic strategies. Vasc Endovascular Surg 41:277-293

8. Wu D, Bassuk J, Arias J, Peschiera I, Lamet A, Kurlansky P, Adams JA 2006 Post-resuscitation reperfusion injury: comparison of periodic $\mathrm{Gz}$ acceleration versus Thumper CPR. Resuscitation 70:454-462

9. Adrie C, Laurent I, Monchi M, Cariou A, Dhainaou JF, Spaulding C 2004 Postresuscitation disease after cardiac arrest: a sepsis-like syndrome? Curr Opin Crit Care 10:208-212

10. Angelos MG, Menegazzi JJ, Callaway CW 2001 Bench to bedside: resuscitation from prolonged ventricular fibrillation. Acad Emerg Med 8:909-924

11. Negovsky VA 1988 Postresuscitation disease. Crit Care Med 16:942-946

12. Gross GJ, Auchampach JA 2007 Reperfusion injury: does it exist? J Mol Cell Cardiol 42:12-18

13. Kloner RA, Dow J, Bhandari A 2006 Postconditioning markedly attenuates ventricular arrhythmias after ischemia-reperfusion. J Cardiovasc Pharmacol Ther 11:55-63

14. Couvreur N, Lucats L, Tissier R, Bize A, Berdeaux A, Ghaleh B 2006 Differential effects of postconditioning on myocardial stunning and infarction: a study in conscious dogs and anesthetized rabbits. Am J Physiol Heart Circ Physiol 291:H1345-H1350

15. Kin H, Zhao ZQ, Sun HY, Wang NP, Corvera JS, Halkos ME, Kerendi F, Guyton RA, Vinten-Johansen J 2004 Postconditioning attenuates myocardial ischemiareperfusion injury by inhibiting events in the early minutes of reperfusion. Cardiovasc Res 62:74-85

16. Sackner MA, Gummels E, Adams JA 2005 Nitric oxide is released into circulation with whole-body, periodic acceleration. Chest 127:30-39

17. Adams JA, Bassuk J, Wu D, Grana M, Kurlansky P, Sackner MA 2005 Periodic acceleration: effects on vasoactive, fibrinolytic, and coagulation factors. J Appl Physiol 98:1083-1090

18. Adams JA, Moore JE Jr, Moreno MR, Coelho J, Bassuk J, Wu D 2003 Effects of periodic body acceleration on the in vivo vasoactive response to N-omega-nitro-Larginine and the in vitro nitric oxide production. Ann Biomed Eng 31:1337-1346

19. Martinez A, Arias J, Bassuk JA, Wu H, Kurlansky P, Adams JA 2008 Adrenomedullin is increased by pulsatile shear stress on the vascular endothelium via periodic acceleration (pGz). Peptides 29:73-78

20. Hamid SA, Baxter GF 2005 Adrenomedullin limits reperfusion injury in experimental myocardial infarction. Basic Res Cardiol 100:387-396

21. Burley DS, Hamid SA, Baxter GF 2007 Cardioprotective actions of peptide hormones in myocardial ischemia. Heart Fail Rev 12:279-291

22. Johnson G III, Furlan LE, Aoki N, Lefer AM 1990 Endothelium and myocardial protecting actions of taprostene, a stable prostacyclin analogue, after acute myocardial ischemia and reperfusion in cats. Circ Res 66:1362-1370

23. Jugdutt BI 1981 Effect of PGE1, PGE2 and PGI2 on ventricular arrhythmias during myocardial infarction in conscious dogs: relation to infarct size. Prostaglandins Med $7: 431-455$

24. Woditsch I, Schror K 1992 Prostacyclin rather than endogenous nitric oxide is a tissue protective factor in myocardial ischemia. Am J Physiol 263:H1390-H1396

25. Lefer DJ, Nakanishi K, Johnston WE, Vinten-Johansen J 1993 Antineutrophil and myocardial protecting actions of a novel nitric oxide donor after acute myocardial ischemia and reperfusion of dogs. Circulation 88:2337-2350

26. Schulz R, Kelm M, Heusch G 2004 Nitric oxide in myocardial ischemia/reperfusion injury. Cardiovasc Res 61:402-413

27. Birnbaum Y, Ye Y, Rosanio S, Tavackoli S, Hu ZY, Schwarz ER, Uretsky BF 2005 Prostaglandins mediate the cardioprotective effects of atorvastatin against ischemiareperfusion injury. Cardiovasc Res 65:345-355

28. Nomura F, Matsuda H, Shirakura R, Ohtani M, Sawa Y, Nakano S, Kawashima Y 1991 Experimental evaluation of myocardial protective effect of prostacyclin analog (OP-41483) as an adjunct to cardioplegic solution. J Thorac Cardiovasc Surg 101:860-865

29. Veeravalli KK, Akula A, Kota MK 2003 Nitric oxide- and prostaglandin-mediated cardioprotection by bradykinin in myocardial ischemia and reperfusion injury. Pol J Pharmacol 55:1021-1029

30. Rastaldo R, Pagliaro P, Cappello S, Penna C, Mancardi D, Westerhof N, Losano G 2007 Nitric oxide and cardiac function. Life Sci 81:779-793

31. Rodriguez-Sinovas A, Abdallah Y, Piper HM, Garcia-Dorado D 2007 Reperfusion injury as a therapeutic challenge in patients with acute myocardial infarction. Heart Fail Rev 12:207-216
32. Liu X, Huang Y, Pokreisz P, Vermeersch P, Marsboom G, Swinnen M, Verbeken E Santos J, Pellens M, Gillijns H, Van de Werf F, Bloch KD, Janssens S 2007 Nitric oxide inhalation improves microvascular flow and decreases infarction size after myocardial ischemia and reperfusion. J Am Coll Cardiol 50:808-817

33. Penna C, Mancardi D, Tullio F, Pagliaro P 2008 Postconditioning and intermitten bradykinin induced cardioprotection require cyclooxygenase activation and prostacyclin release during reperfusion. Basic Res Cardiol, in press

34. Adams JA, Mangino MJ, Bassuk J, Inman DM, Sackner MA 2000 Noninvasive motion ventilation (NIMV): a novel approach to ventilatory support. J Appl Physiol 89:2438-2446

35. Adams JA, Mangino MJ, Bassuk J, Kurlansky P, Sackner MA 2001 Novel CPR with periodic Gz acceleration. Resuscitation 51:55-62

36. Nava G, Adams JA, Bassuk J, Wu D, Kurlansky P, Lamas GA 2005 Echocardiographic comparison of cardiopulmonary resuscitation (CPR) using periodic acceleration (pGz) versus chest compression. Resuscitation 66:91-97

37. Schiller NB, Shah PM, Crawford M, DeMaria A, Devereux R, Feigenbaum H, Gutgesell H, Reichek N, Sahn D, Schnittger I 1989 Recommendations for quantitation of the left ventricle by two-dimensional echocardiography. American Society of Echocardiography Committee on Standards, Subcommittee on Quantitation of Two-Dimensional Echocardiograms. J Am Soc Echocardiogr 2:358-367

38. Carluccio E, Tommasi S, Bentivoglio M, Buccolieri M, Prosciutti L, Corea L 2000 Usefulness of the severity and extent of wall motion abnormalities as prognostic markers of an adverse outcome after a first myocardial infarction treated with thrombolytic therapy. Am J Cardiol 85:411-415

39. Galasko GI, Basu S, Lahiri A, Senior R 2001 A prospective comparison of echocardiographic wall motion score index and radionuclide ejection fraction in predicting outcome following acute myocardial infarction. Heart 86:271-276

40. Magnotti LJ, Upperman JS, Xu DZ, Lu Q, Deitch EA 1998 Gut-derived mesenteric lymph but not portal blood increases endothelial cell permeability and promotes lung injury after hemorrhagic shock. Ann Surg 228:518-527

41. Adams JA, Mangino MJ, Bassuk J, Kurlansky P, Sackner MA 2001 Regional blood flow during periodic acceleration. Crit Care Med 29:1983-1988

42. Adams JA, Bassuk JA, Arias J, Wu H, Jorapur V, Lamas GA, Kurlansky P 2007 Periodic acceleration (pGz) CPR in a swine model of asphyxia induced cardiac arrest short-term hemodynamic comparisons. Resuscitation 77:132-138

43. Vinten-Johansen J 2007 Postconditioning: a mechanical maneuver that trigger biological and molecular cardioprotective responses to reperfusion. Heart Fail Rev $12: 235-244$

44. Vinten-Johansen J, Zhao ZQ, Zatta AJ, Kin H, Halkos ME, Kerendi F 2005 Postconditioning-a new link in nature's armor against myocardial ischemiareperfusion injury. Basic Res Cardiol 100:295-310

44a. Na HS, Kim YI, Yoon YW, Han HC, Nahm SH, Hong SK 1996 Ventricular premature beat-driven intermitlent restoration of coronary blood flow reduces the incidence of reperfusion-indeed ventricular fibrillation in a cat model of regiona ischemia. Am Heart J 132:78-83

45. Zhao ZQ, Corvera JS, Halkos ME, Kerendi F, Wang NP, Guyton RA, VintenJohansen J 2003 Inhibition of myocardial injury by ischemic postconditioning during reperfusion: comparison with ischemic preconditioning. Am J Physiol Heart Circ Physiol 285:H579-H588

46. Yellon DM, Hausenloy DJ 2007 Myocardial reperfusion injury. N Engl J Med 357:1121-1135

47. Hausenloy DJ, Yellon DM 2007 Reperfusion injury salvage kinase signalling: taking a RISK for cardioprotection. Heart Fail Rev 12:217-234

48. Hausenloy DJ, Yellon DM 2007 Preconditioning and postconditioning: united at reperfusion. Pharmacol Ther 116:173-191

49. Tsang A, Hausenloy DJ, Yellon DM 2005 Myocardial postconditioning: reperfusion injury revisited. Am J Physiol Heart Circ Physiol 289:H2-H7

50. Vinten-Johansen J, Zhao ZQ, Jiang R, Zatta AJ 2005 Myocardial protection in reperfusion with postconditioning. Expert Rev Cardiovasc Ther 3:1035-1045

51. Tsang A, Hausenloy DJ, Mocanu MM, Yellon DM 2004 Postconditioning: a form of "modified reperfusion" protects the myocardium by activating the phosphatidylinositol 3-kinase-Akt pathway. Circ Res 95:230-232

52. Zhu M, Feng J, Lucchinetti E, Fischer G, Xu L, Pedrazzini T, Schaub MC, Zaugg M 2006 Ischemic postconditioning protects remodeled myocardium via the PI3K$\mathrm{PKB} / \mathrm{Akt}$ reperfusion injury salvage kinase pathway. Cardiovasc Res 72:152-162

53. Yang XM, Proctor JB, Cui L, Krieg T, Downey JM, Cohen MV 2004 Multiple, brief coronary occlusions during early reperfusion protect rabbit hearts by targeting cell signaling pathways. J Am Coll Cardiol 44:1103-1110

54. Wu D, Bassuk J, Arias J, Kurlansky P, Lozano H, Lamas G, Adams JA 2007 Different roles of nitric oxide synthase isoforms in cardiopulmonary resuscitation in pigs. Resuscitation 73:144-153

55. Lozano H, Wu D, Bassuk J, Aria J, Kurlansky P, Lamas GA, Adams JA 2008 The effects of prostaglandin inhibition on whole-body ischemia-reperfusion in swine. Am J Emerg Med 26:45-53 